\title{
Effect of longterm placebo controlled calcium supplementation on sigmoidal cell proliferation in patients with sporadic adenomatous polyps
}

\author{
U M Weisgerber, H Boeing, R W Owen, R Waldherr, R Raedsch, J Wahrendorf
}

\begin{abstract}
A longterm, double blind intervention trial was undertaken in patients with sporadic adenoma treated by polypectomy to investigate the putative role of calcium as a protective factor in colon carcinogenesis. The aim of the study was to assess the effect of a daily dietary supplementation of $2 \mathrm{~g}$ calcium over nine months on cell proliferation measured as proliferation index in colonic mucosa. A total of 48 patients were entered into the study of which 30 were fully compliant. After intervention proliferation index \% (mean (SEM) in colonic epithelium was decreased in both the calcium $(13.5(1.5)$ to $11.4(1.2))$ and the placebo group $(13.7(0.9)$ to $10.8(1 \cdot 1))$. The difference in the change between the two groups was not significant $(p=0 \cdot 7)$. Changes in proliferation index $\%$ of crypt compartments were also not significantly different between the two groups. A significantly positive correlation between soluble calcium in faeces and the total proliferation index $\%$ in colonic epithelium at baseline and after intervention $(r=0.54$, $\mathbf{p}<0.01, r=0.50, p<0.01$ respectively) suggests that an increase of free luminal calcium alone is insufficient for inhibition of cellular proliferation.
\end{abstract}

(Gut 1996; 38: 396-402)

Keywords: calcium, cell proliferation, colorectal cancer, vitamin $\mathrm{D}$, chemoprevention.

Human Nutrition, Unit of Medical

Epidemiology,

Bergholz-Rehbrücke,

Germany

$\mathrm{H}$ Boeing

Division of Toxicology and Cancer Risk

Factors, German

Cancer Research

Centre, Heidelberg,

Germany

R W Owen

Institute of Pathology, University of

Heidelberg,

Heidelberg, Germany

$\mathrm{R}$ Waldherr

St Josef Hospital, Wiesbaden, Germany R Raedsch

Correspondence to: Dr R W Owen, Division of Toxicology and Cancer Risk Factors, German Cancer Factors, German Cance Research Centre, Im Deuenheimer Feld 280 D-69120 Heidelberg, Germany.

Accepted for publication 28 September 1995

Cell proliferation is increased in colonic epithelium of patients at high risk for colorectal cancer, such as in patients with sporadic colorectal adenomas ${ }^{1-3}$ or carcinomas, ${ }^{45}$ ulcerative colitis, ${ }^{67}$ familial adenomatous polyposis (FAP) patients, ${ }^{8}$ or first degree relatives of colon cancer patients. ${ }^{9}$ Intestinal hyperproliferation is therefore regarded as an early stage in preneoplastic development. Calcium may reduce colorectal epithelial proliferation and thereby act as a chemopreventive agent in colorectal cancer. ${ }^{10}$ Calcium intervention studies in high risk patients using proliferation markers as intermediate end points of carcinogenesis have as yet produced inconsistent results. Several short-term studies (duration $\leqslant 3$ months) showed a decreasing effect of calcium supplementation on colonic cell proliferation, ${ }^{10-14}$ whereas others did not show a protective effect. ${ }^{1516}$ Out of a small number of longterm studies, ${ }^{17-19}$ only one placebo controlled intervention in FAP patients was able to show a reduction in crypt cell production rate in the rectal epithelium. ${ }^{18}$ Furthermore, except for one short-term study relating to cell proliferation in the sigmoid colon, ${ }^{14}$ the effect of calcium supplementation has been confined to the rectum.

The aim of this study was to investigate if intervention with $2 \mathrm{~g}$ calcium/day over a period of nine months would decrease cell proliferation in the sigmoid mucosa of patients treated by polypectomy using a randomised, double blind, placebo controlled protocol. Correlation of proliferative activity at baseline with known risk factors such as age, adenoma size, and grade of dysplasia was also investigated.

\section{Methods}

\section{Study design}

Participants were recruited over a period of nine months from patients attending endoscopic units in eight hospitals in Heidelberg and surrounding areas with one physician being responsible for recruiting patients and biopsying in each hospital. Patients with newly diagnosed colorectal adenomas who were 30-75 years of age were eligible for the study. Additional inclusion criteria were a histologically confirmed adenomatous polyp larger than $4 \mathrm{~mm}$, informed consent about participation in the study, and biopsy for determination of cell proliferation. Biopsy specimens were obtained at the initial colonoscopy from macroscopically normal mucosa at the rectosigmoidal junction (about $20 \mathrm{~cm}$ from the anal verge) but at least $5 \mathrm{~cm}$ from any neoplastic lesion, using standard forceps. Number, size, and localisation of polyps and whether or not they were removed, were recorded.

Exclusion criteria included conditions predisposing to colorectal cancer other than sporadic adenomas, contraindications to calcium supplementation or to biopsy sample excision, conditions indicating severe restriction of general health, or drug use that may interfere with the study. In particular, exclusion criteria were as follows: FAP; inflammatory bowel disease; chronic alcohol abuse; intestinal malabsorption syndromes; cancer other than nonmelanoma skin cancer; renal insufficiency; gastrectomy, ileostomy, colectomy; vegetarian diet; consumption of more than 1 litre milk per day or more than $600 \mathrm{~g}$ dairy products per day (milk-alkali-syndrome); renal stones, haematuria; sarcoidosis; hyperparathyroidism; hypercalcaemia; abnormal serum calcium or creatinine concentrations at the time of initial 
colonoscopy; cholestyramine treatment; calcium or vitamin D supplementation; anticoagulant treatment, problems in understanding the nature of the study; and place of residence more than $100 \mathrm{~km}$ from the study centre.

Eligible patients were followed up immediately after the initial polypectomy and subsequently every three months at their private residences. Before entering the actual treatment phase, participants were asked to collect 48 hour stool and 24 hour urine samples. The usual dietary intake was assessed with a self administered food frequency questionnaire. Study participants were asked to continue their normal Western style diet. Before randomisation, a run in phase of three months was applied in which all participants received placebo. Less than $80 \%$ compliance to the treatment protocol during the run in phase resulted in exclusion from randomisation. Compliant participants were then randomly allocated to either calcium or placebo treatment for another nine months. At every follow up visit, two 24 hour recalls were conducted to monitor short-term changes in dietary habits. Treatment compliance was assessed by pill count. Drug intake besides calcium supplementation was assessed at entry into the study and every three months during follow up. Faecal (48 hour) and 24 hour urine samples were again collected after nine months. After a total of 12 months - that is, three months run in phase and nine months calcium supplementation - a control colonoscopy was performed during which biopsy samples were again obtained at $20 \mathrm{~cm}$ proximal to the anal verge for final examination. The study was approved by the ethical committee of the University of Heidelberg.

\section{Medication and randomisation}

Calcium was applied in the form of effervescent tablets as calcium-glucono-lactate, with each tablet containing $1000 \mathrm{mg}$ calcium. Participants were requested to take one with their breakfast and one with their evening meal, resulting in a daily supplementation dose of $2000 \mathrm{mg}$ calcium. Placebo tablets consisted mainly of citrate, fructose, and sucrose. Both calcium and placebo medication were kindly provided by Sandoz AG, Nürnberg, Germany.

Randomisation was conducted in advance. Each box of medication covered three months intervention and was labelled by randomly selected numbers. Thus, the study coordinator and interviewer were blinded throughout the study. Participants allocated to calcium treatment did not detect any difference in medication appearance when calcium supplements were introduced after the run in phase.

\section{Collection and preparation of faecal and urine samples}

Faecal samples were defecated into plastic bowls and placed immediately on dry ice $\left(-79^{\circ} \mathrm{C}\right)$. The complete 48 hour sample was stored at $-80^{\circ} \mathrm{C}$ until further analysis. For aliquoting, samples were thawed overnight at $4^{\circ} \mathrm{C}$, pooled, and homogenised at room temperature in a rotating homogeniser (Heidolph, Kelheim, Germany) at $600 \mathrm{rpm}$ for five minutes. Aliquots of $40 \mathrm{~g}$ were freeze dried, reweighed, and ground to a fine, homogeneous powder. Urine was collected over 24 hours, aliquoted, and stored at $-20^{\circ} \mathrm{C}$ until further analysis.

\section{Calcium analysis}

To $100 \mathrm{mg}$ of freeze dried faeces $2 \mathrm{ml}$ of concentrated $\mathrm{HNO}_{3}$ was added in a tightly sealed universal bottle. The bottles were placed in a heating block at $120^{\circ} \mathrm{C}$ for one hour. On cooling $10 \mathrm{ml} 1 \mathrm{M} \mathrm{HCl}$ was added prior to analysis of total calcium by atomic absorption spectrophotometry (AAS). Soluble calcium was measured by adding $10 \mathrm{ml}$ of distilled water to $100 \mathrm{mg}$ of freeze dried faeces and incubating overnight at room temperature. Supernatants were again analysed by AAS.

\section{Dietary analysis}

During the basic examination a food frequency questionnaire for self administration was distributed to each participant. This questionnaire asked for the frequency and portion size of 121 food items. The resulting quantity in food consumption was converted into nutrient intake by using a German food composition table (Federal Food Code of Germany). This Food Code has been developed by the Federal Health Office and encompasses a coding system of more than 10000 different food codes with the nutrient data for each food code. This version of the food frequency questionnaire was not formally validated. However, subsequent versions showed similar characteristics in terms of validity and reliability compared with other published food frequency questionnaires ( $\mathrm{H}$ Boeing, unpublished data).

During supplementation the 24 hour recall method was used. At each follow up visit participants were asked about their food intake on the previous day. For each single food item consumed, the amount was estimated by use of household measures or portion size photos. A cross check at the end of each 24 hour recall was applied to search for previously omitted items. The detailed responses were coded according to the Federal Food Code and subsequently converted into nutrient intake.

\section{Determination of proliferation index}

For the first five patients who entered the study, cell proliferation was measured by the BrdU method. To facilitate recruitment of patients from external hospitals, however, a proliferation marker based on an endogenous cell cycle related antigen was required to circumvent immediate incubation of viable tissue. Therefore, PCNA (clone PC10) immunohistochemistry was applied for the subsequent study participants. In any one patient, the same method was used before and after intervention. After clinical examination and, as for BrdU incubation of biopsy samples, 
the specimens were fixed in absolute methanol, transported to the laboratory, and processed within 24 hours. Both BrdU and PCNA protocols have been described and compared elsewhere. ${ }^{20}$

All sections were examined by one observer who had no knowledge of the clinical features, the histological diagnosis or the random allocation to treatment groups. In a previously conducted analysis of variance ${ }^{20}$ the number of crypts and number of biopsy samples that must be evaluated to classify a subject within a certain interval was estimated. According to these findings, five crypts of each biopsy sample were evaluated whenever three samples were used for the evaluation, eight crypts of each of two biopsy samples, and 30 crypts when only one biopsy sample was available to characterise a subject at each point in time.

A crypt was analysed if its entire length was visible in the longitudinal section and the base contacted the muscularis mucosae. In each crypt column (which is the single column of epithelial cells lining one side of a sectioned crypt meeting the criteria) the total number of cells and the number of labelled cells and their position in the crypt column relative to the base of the crypt were noted. Total number of cells, number of labelled cells, and PI\%, which is the ratio of labelled cells to the total number of cells, were determined for each crypt column. PIs were also calculated separately for each of five compartments of equal size into which each crypt column was divided. The same procedure was repeated for percentiles of the crypt column of standardised length, and a running mean over five percentiles was calculated to smooth the distribution.

\section{Sample size considerations}

For sample size calculations the two sided $t$ test for unpaired samples was used to test for significance of the difference in the mean change of $\mathrm{PI} \%$ from the baseline value after intervention between the two treatment groups. The standard deviation (SD) of the major end point 'change in PI\% after intervention as compared to baseline' was estimated to be around 2, based on data by Gregoire et $a l,{ }^{15}$ who gave a standard deviation of the mean change after intervention in the placebo group of 1.7 and in the calcium group of $2 \cdot 3$. With $\alpha=0.05$ and $\beta=0 \cdot 1$, the number of patients required to detect a difference of 2 in the change of PI\% between two groups was calculated to be 21 patients in each group. ${ }^{21}$ To account for drop outs during the study, a total of 50 patients was planned to be recruited for the study.

\section{Statistical analysis}

Baseline correlation analysis was conducted treating age, number of adenomas, size of the largest adenoma, and faecal calcium concentration as continuous variables and grade of dysplasia (tubular/tubulo-villous/villous) as a categorical variable.

For comparison between the two groups, dietary data were adjusted for sex. For each
TABLE I Age, sex, and dietary data prior to intervention in calcium and placebo group (mean (SD))

\begin{tabular}{lcc}
\hline & $\begin{array}{l}\text { Placebo group } \\
(n=15)\end{array}$ & $\begin{array}{l}\text { Calcium group } \\
(n=15)\end{array}$ \\
\hline Age & $63 \cdot 3(6 \cdot 1)$ & $60 \cdot 9(9 \cdot 2)$ \\
No of female patients & 10 & 4 \\
Dietary intake & & \\
Energy (kJ/d) & $10410(2169)$ & $11678(5788)$ \\
Protein (g/d) & $93(27)$ & $99(50)$ \\
Fat $(g / d)$ & $97(38)$ & $105(51)$ \\
Carbohydrates $(g / d)$ & $253(52)$ & $293(160)$ \\
Fibre $(g / d)$ & $31(7)$ & $35(20)$ \\
Calcium $(\mathrm{mg} / \mathrm{d})$ & $933(416)$ & $922(370)$ \\
Vitamin D $(\mu \mathrm{g} / \mathrm{d})$ & $4(4)$ & $4(3)$ \\
& & \\
\hline
\end{tabular}

*As determined by food frequency questionnaire before intervention, adjusted for sex.

nutrient (j), a regression model was calculated with sex ( $x)$ as dependent variable (coded as 1 and 2): $y_{j}=\alpha_{\mathfrak{j}}+\beta_{\mathfrak{j}} \mathrm{x}$. Intercept $\left(\alpha_{\mathfrak{j}}\right)$ and slope $\left(\beta_{\mathfrak{j}}\right)$ parameters were used to adjust each patient's intake values (i) for each nutrient, thereby simulating a group of balanced sex:

$$
y_{i j(a d j)}=\frac{y_{i j}-\beta_{j} x_{i}+\left(y_{i j}-\beta_{j} x_{i}\right) \frac{\alpha_{j}+\beta_{j}}{\alpha_{j}}}{2}
$$

Subjects were regarded as compliant and included in the final evaluation of the effect of calcium intervention if the pill count yielded an $80 \%$ adherence to the treatment and the increase in faecal calcium excretion was greater than $1500 \mathrm{mg}$.

Mean PI\% of colonic epithelial cell proliferation was determined for each group at each time point. The treatment effect was estimated and tested with Wilcoxon's rank sum test on the difference between the mean changes of $\mathrm{PI} \%$ in each group after intervention compared with baseline. Average scores were used for ties. Results were considered statistically significant at $\alpha=0 \cdot 05$. Multiple regression analysis was used to adjust for confounding variables. The $\mathrm{PI} \%$ as a function of cell position relative to crypt column base was examined separately for each group at each time point.

\section{Results}

Of 48 patients who were entered into the calcium intervention study, four were not compliant during run in phase, one died, six were not compliant during the main intervention phase and four either refused or were not able to undergo their final examination - that is, biopsy samples could not be obtained. Each of the remaining 33 participants showed a compliance greater than $80 \%$ at each pill count evaluation. In three of these participants, however, calcium excretion in faeces indicated low compliance. They were therefore excluded from the final analysis. The final statistical analysis is based on 30 participants (15 in each group) who completed the study in a full compliant manner ( $>96 \%$ compliance). Table I gives characteristics of the study group with respect to age, sex, and usual dietary intake. The average age of the final study group was 62 (range 46-75), 14 women and 16 men. Mean age of both groups was similar, but distribution of sex 
TABLE II Effect of nine month calcium intervention on total proliferation index (PI\%) and PI\% of crypt compartments in colonic mucosa (mean (SEM))

\begin{tabular}{|c|c|c|c|c|c|c|c|}
\hline & \multicolumn{3}{|c|}{ Placebo group $(n=15)$} & \multicolumn{3}{|c|}{ Calcium group $(n=15)$} & \multirow[b]{2}{*}{${ }_{\text {Value }}$} \\
\hline & $\begin{array}{l}\text { Before } \\
\text { Intervention }\end{array}$ & $\begin{array}{l}\text { After } \\
\text { Intervention }\end{array}$ & Change & $\begin{array}{l}\text { Before } \\
\text { Intervention }\end{array}$ & $\begin{array}{l}\text { After } \\
\text { Intervention }\end{array}$ & Change & \\
\hline $\begin{array}{l}\text { PI\%, total } \\
\text { PI\%, compartment } 1 \\
\text { PI\%, compartment } 2 \\
\text { PI\%, compartment } 3 \\
\text { PI\%, compartment } 4 \\
\text { PI\%, compartment } 5 \\
\text { No of cells per hemicrypt, total }\end{array}$ & $\begin{array}{r}13 \cdot 7(0 \cdot 9) \\
22 \cdot 7(1 \cdot 8) \\
27 \cdot 3(2 \cdot 6) \\
14 \cdot 4(1 \cdot 1) \\
3 \cdot 4(0 \cdot 5) \\
0 \cdot 7(0 \cdot 4) \\
62 \cdot 4(8 \cdot 4)\end{array}$ & $\begin{array}{l}10 \cdot 7(1 \cdot 1) \\
18 \cdot 8(2 \cdot 0) \\
21 \cdot 5(1 \cdot 8) \\
10 \cdot 4(1 \cdot 6) \\
2 \cdot 3(0 \cdot 5) \\
0 \cdot 7(0 \cdot 3) \\
62 \cdot 0(11 \cdot 0)\end{array}$ & $\begin{array}{l}-3 \cdot 0(1 \cdot 0) \\
-3.9(1 \cdot 8) \\
-5 \cdot 8(2 \cdot 1) \\
-4 \cdot 0(2 \cdot 0) \\
-1 \cdot 1(0 \cdot 8) \\
+0 \cdot 05(0 \cdot 4) \\
-1 \cdot 3(2 \cdot 6)\end{array}$ & $\begin{array}{l}13.5(1 \cdot 5) \\
19.9(2 \cdot 2) \\
28 \cdot 2(2 \cdot 8) \\
14.9(2 \cdot 2) \\
3.7(0 \cdot 9) \\
0.6(0 \cdot 2) \\
63.8(10 \cdot 0)\end{array}$ & $\begin{array}{r}11 \cdot 4(1 \cdot 2) \\
19 \cdot 4(2 \cdot 1) \\
23 \cdot 1(2 \cdot 4) \\
11 \cdot 3(1 \cdot 6) \\
2 \cdot 6(0 \cdot 8) \\
0.5(0 \cdot 2) \\
64 \cdot 0(8 \cdot 9)\end{array}$ & $\begin{array}{l}-2 \cdot 1(1 \cdot 5) \\
-0 \cdot 5(1 \cdot 7) \\
-5 \cdot 1(3 \cdot 1) \\
-3 \cdot 6(2 \cdot 5) \\
-1 \cdot 1(1 \cdot 1) \\
-0 \cdot 2(0 \cdot 3) \\
-0 \cdot 1(3 \cdot 0)\end{array}$ & $\begin{array}{l}0 \cdot 7 \\
0 \cdot 2 \\
0 \cdot 4 \\
0 \cdot 5 \\
0 \cdot 6 \\
0 \cdot 8 \\
0 \cdot 5\end{array}$ \\
\hline
\end{tabular}

*Wilcoxon's rank sum test on the difference between the changes in both groups.

was unbalanced (Table I). For comparison, dietary data were therefore adjusted for sex. In the calcium group usual energy, protein, fat, carbohydrate, and fibre intake were slightly higher than in the placebo group, whereas the calcium intake was lower. However, a wide variation of mean values rendered these differences insignificant. Dietary habits during the study ascertained by repeated 24 hour recalls were stable in both groups (detailed data not shown). Drugs or dietary supplements that could potentially affect cell proliferation were only taken in the calcium group (two participants with vitamin $E$ and $C$ supplements and one with $\beta$-sitosterol supplement for at least three months; anti-inflammation drugs were never taken by any participant).

Multivariate analysis showed age of patients and size of largest adenoma at initial examination to be significantly positively associated
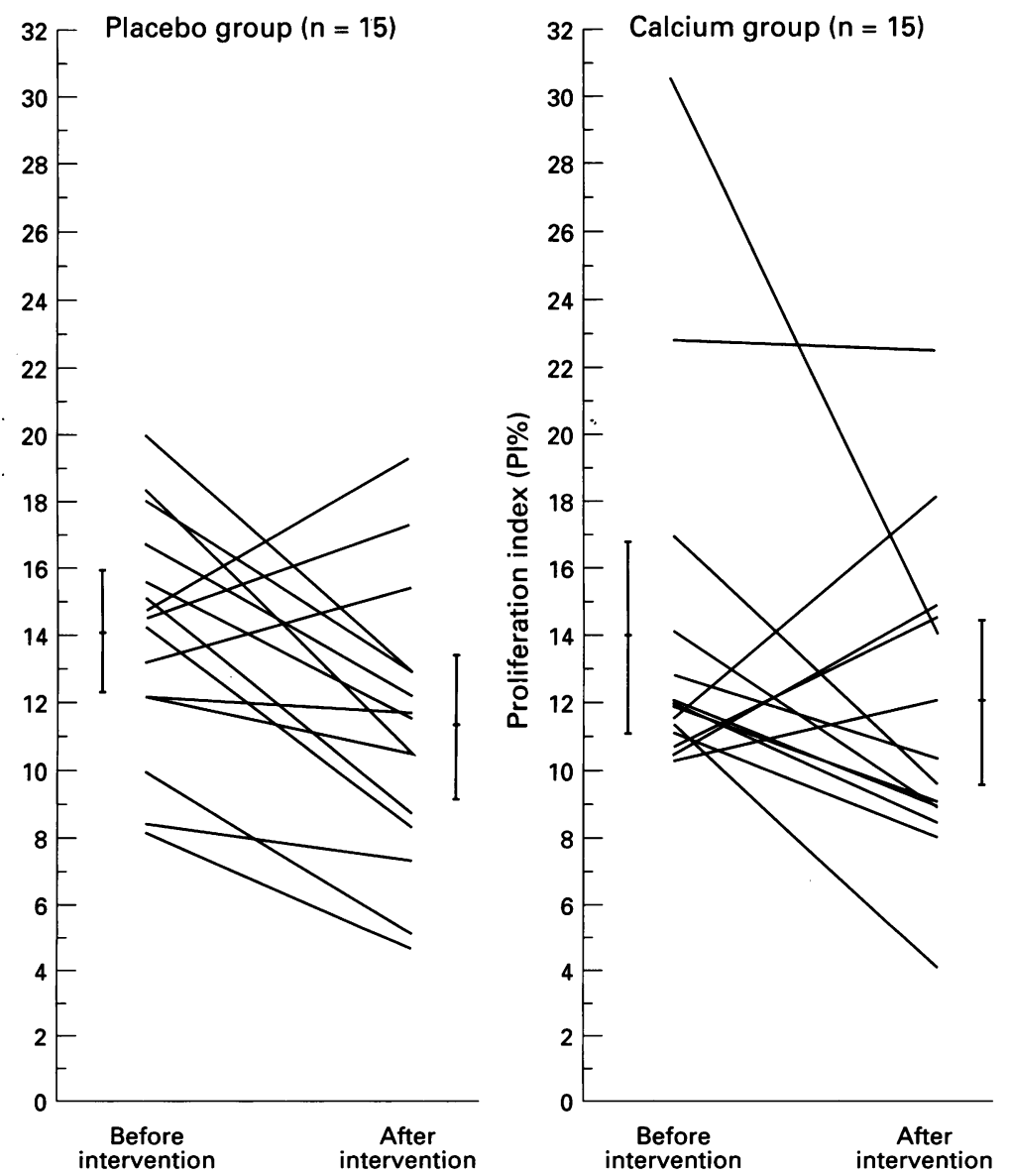

Figure 1: Individual and mean PI\% (with SEM) in colonic mucosa of 30 adenoma patients before and after nine months of calcium intervention separate for calcium and placebo group. with initial $\mathrm{PI} \%(r=0.49, \mathrm{p}<0.01 ; r=0.51$, $\mathrm{p}<0.01$ respectively). No association could be found between cell proliferation and number of adenoma, grade of dysplasia in removed adenoma or distance of rectosigmoidal junction to the nearest adenoma. The method of measuring cell proliferation was included in each multivariate model, because BrdU generally yielded lower PIs than PCNA. At baseline examination as well as after intervention, a significant positive correlation was seen between concentration of soluble calcium in faeces and PI\% in sigmoidal mucosa $(r=0.54$, $\mathrm{p}<0.01, r=0.50, \mathrm{p}<0.01)$. Subdivided into crypt compartments, this correlation between soluble calcium and $\mathrm{PI} \%$ was only significant for compartment 1 and 2 .

The power of the study was diminished for two reasons. Firstly, only 15 patients completed the study according to protocol in each group rather than the intended 21 . Secondly, standard deviation of the major end point 'change in PI\% after intervention as compared to baseline' was larger than anticipated. The minimum detectable difference of PI\% between both groups in this study with $n=15$ in each group and $\mathrm{SD}=4 \cdot 75$ was $4 \cdot 8$. Given an expected no effect in the placebo group, a decrease of $\mathrm{PI} \%$ in the calcium group to approximately $7 \%$ of that found in healthy controls ${ }^{20}$ could have been detected as statistically significant compared with the placebo group.

After nine months of intervention a decrease of total $\mathrm{PI} \%$ in sigmoidal mucosa was evident in both calcium (from 13.5 before to 11.4 after intervention) and placebo group (from 13.7 to 10.7) (Table II). The difference between the two groups regarding the change of PI\% after intervention compared with baseline, was not statistically significant $(p=0 \cdot 7)$. The observed decrease in the calcium group could therefore not be ascribed to calcium intervention. Age, sex, and adenoma size did not influence this result when included as covariables in a regression analysis. The method of measuring cell proliferation had no influence on the change in $\mathrm{PI} \%$ after intervention - that is, did not interfere with the main result. Five of 15 patients in the calcium group but only three of 15 in the placebo group experienced an increase in $\mathrm{PI} \%$ (Fig 1). There was a tendency in the calcium group for initially high values to decrease and initially low values to increase.

Proliferative activity in crypt compartments was highest in compartment 2 in both groups 

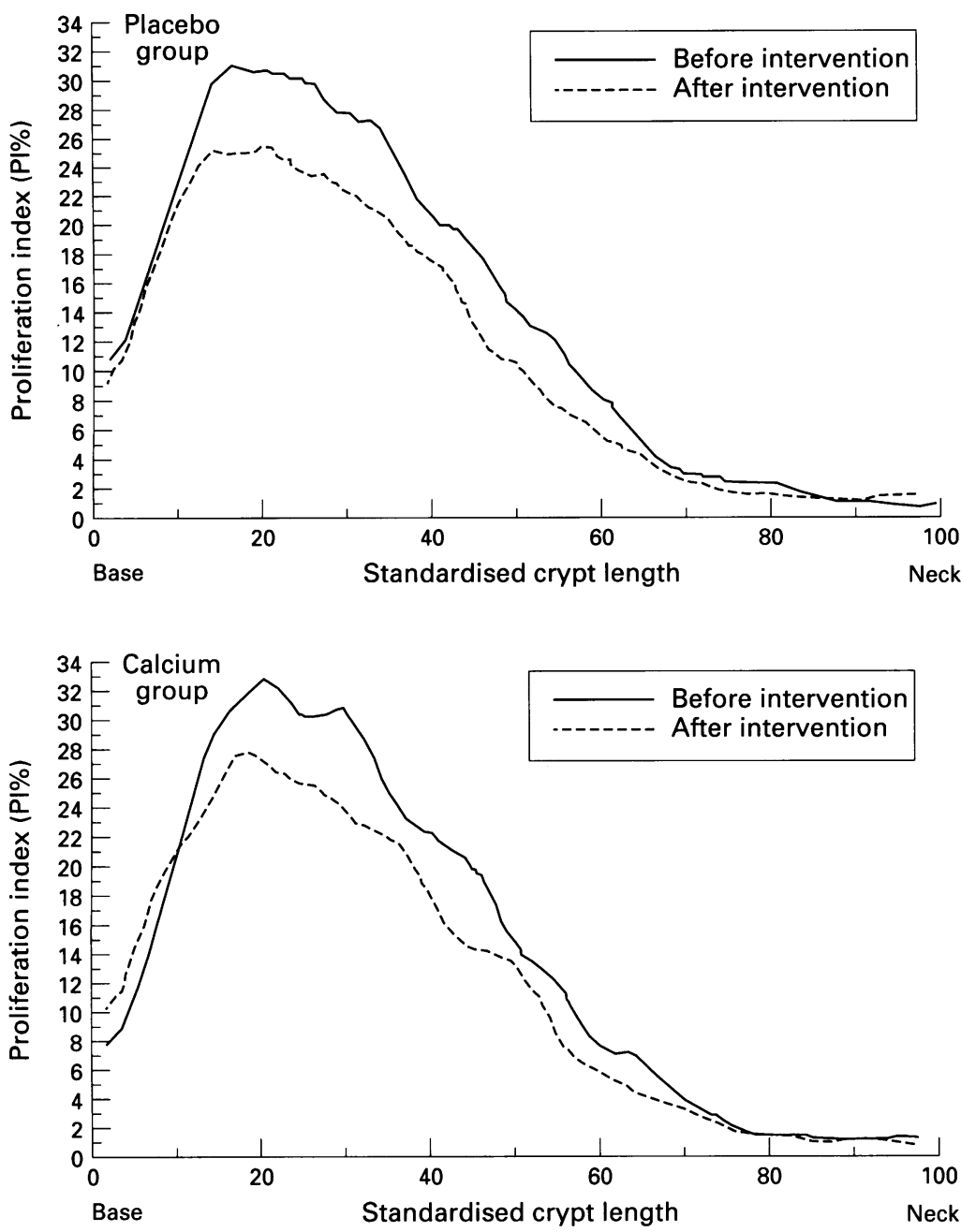

Figure 2: Proliferation index as a function of the percentile distance from the base of the crypt column before and after nine months of calcium intervention separate for calcium and placebo group (curve smoothed by a running mean of five).

of patients at both time points (Table II). PI\% decreased in both groups during intervention in compartments 2,3 , and 4 , whereas for the basal compartment 1 , a decrease was only evident in the placebo group (Table II). This indicates a slight downward shift of the proliferative zone in the crypt due to calcium supplementation. However, the differences between the calcium and placebo groups regarding the change in each compartment were not statistically significant. In compartment 5, PI\% remained unchanged after intervention. Also, total number of cells per crypt column was not affected by intervention.

The two groups were also compared at the two different time points regarding the continuous distribution of labelled cells along the crypt (Fig 2). Before intervention, a steep rise in proportion of labelled cells occurred to a maximum at the 20 th percentile in the calcium group and the 18 th percentile in the placebo group. After intervention the peak PI reverted to the 18th percentile of crypt height in the calcium group, whereas in the placebo group the maximum PI\% could be found at the 20 th percentile. In both groups there was a decrease of proliferative activity after intervention compared with baseline almost along the whole length of the crypt, except for the uppermost $20 \%$ and the basal $10 \%$ of the crypt. However, these differences were not significant at any cell position.

An intention to treat analysis of all randomised subjects was not possible, because five non-compliant and four compliant subjects refused to or were not able to undergo final examination - that is, biopsy samples could not be obtained. Because the study was conducted in symptom free subjects, it is very unlikely that compliance rate is related to the outcome measure. Four subjects with less than ideal compliance $(<80 \%)$ did have a final examination and biopsy. Including their data in the analysis did not materially effect the results.

Daily calcium excretion in faeces increased significantly both as total calcium and soluble calcium in the calcium group compared with the corresponding change in the placebo group (Table III). The increase in faecal calcium output of $1807 \mathrm{mg}$ in the calcium group corresponds closely to $2000 \mathrm{mg}$ calcium by which the diet was supplemented.

Calcium excretion in urine before intervention was in both groups on average $85 \mathrm{mg} /$ day (Table III), which is well below the obligatory amount of renal calcium loss under conditions of calcium balance (114-116 mg/day), 22 showing a negative calcium balance in these patients. After intervention with $2 \mathrm{~g}$ calcium per day for six months renal calcium excretion stayed below this level in the calcium group and the increase was not significantly different from that in the placebo group.

\section{Discussion}

This study shows that independent of intervention, cell proliferation (measured predominantly by PCNA immunohistochemistry) in colonic mucosa of adenoma patients correlates positively with patient age and size of the largest diagnosed adenoma. This association with known risk factors for colorectal

TABLE III Effect of six month calcium (2 g/d) intervention on calcium excretion in faeces and urine in adenoma patients (mg/d) (mean (SEM))

\begin{tabular}{|c|c|c|c|c|c|c|c|}
\hline & \multicolumn{3}{|c|}{ Placebo group $(n=15)$} & \multicolumn{3}{|c|}{ Calcium group $(n=14) \dagger$} & \multirow[b]{2}{*}{$\stackrel{p}{\text { Value }}^{\star}$} \\
\hline & $\begin{array}{l}\text { Before } \\
\text { intervention }\end{array}$ & $\begin{array}{l}6 \text { Months after } \\
\text { intervention }\end{array}$ & Change & $\begin{array}{l}\text { Before } \\
\text { intervention }\end{array}$ & $\begin{array}{l}6 \text { Months after } \\
\text { intervention }\end{array}$ & Change & \\
\hline \multicolumn{8}{|l|}{ Faeces } \\
\hline Total calcium & $914(141)$ & $723(78)$ & $-192(112)$ & $1021(170)$ & $2828(316)$ & $+1807(357)$ & $<0.001$ \\
\hline Water soluble calcium & $114(23)$ & $100(16)$ & $-40(18)$ & $130(28)$ & $337(158)$ & $+206(37)$ & $<0.01$ \\
\hline \multicolumn{8}{|l|}{ Urine } \\
\hline Total calcium & $68(9)$ & $74(11)$ & $+5(9)$ & $100(24)$ & $109(12)$ & $+10(24)$ & $0 \cdot 6$ \\
\hline
\end{tabular}

*Wilcoxon rank sum test on the difference between the changes in both groups. †No collection of faeces and urine in one participant. 
neoplasia supports the idea of the measurement of cell proliferation to be an adequate biomarker for increased colon cancer risk.

The major intention of the study was to investigate whether or not a longterm calcium supplementation would decrease cell proliferation in the sigmoid mucosa of patients treated by polypectomy. A decrease in cell proliferation was evident in both calcium and placebo groups after nine months of intervention. The power of the study permits the conclusion that a longterm calcium intervention in patients treated by polypectomy is unable to normalise the raised proliferative status in the sigmoid colon of these patients. Both patient recruitment and compliance problems were encountered in this study. Forty eight instead of the intended 50 patients were entered into the study, of which only 30 were fully compliant. The most plausible explanation for low compliance seems to be that the traumatic experience of a polypectomy has only a shortterm effect on most patients' perception of illness. During the course of a one year intervention, a number of other medical, psychological, and social problems emerge, which allows the memory of a previous diagnosis to pale by significance. The longer the study period the more participants begin to consider it less important to continue intervention and drop out. Compliance in short-term studies therefore tends to be higher.

An obvious disadvantage of the study was that two different proliferation markers were used. The method used for an individual patient was shown to influence only the level of $\mathrm{PI} \%$ at a particular point in time, but not the change in $\mathrm{PI} \%$ after intervention compared with baseline. The use of two different markers is therefore very unlikely to have distorted the results.

There are several possible reasons as to why a decrease in cell proliferation in both groups was found independent of medication. Participation in a preventive trial may induce participants to change their health related behaviour, such as diet. ${ }^{23}$ Based on the dietary information ascertained at onset and during the course of this study, it is evident, that participants in both groups continued their normal diets. Alternatively, our findings may be a result of statistical regression to the mean. ${ }^{24}$ However, a prerequisite for regression to the mean to occur, which is a positive correlation between values measured at the two points in time is not met in our data. Another possible explanation for the decrease in cell proliferation in both patient groups is that removal of the neoplastic lesion from the colon may cause general reduction of cellular proliferation along the entire colon. There is some support for this because Risio et $a l^{3}$ found a significant decrease in colonic proliferation as a function of time of a polyp free colon after two years. This may explain why calcium intervention in patients treated with polypectomy without a control group seems effective. ${ }^{14}$

In most calcium intervention studies cell proliferation was measured in the rectum, and results were extrapolated to the risk of developing a neoplastic lesion in the colon. The authors justify this by reference to studies of Terpstra et $a l^{25}$ and Ponz de Leon et al. ${ }^{26}$ Both showed increased cell proliferation in high risk patients not only in mucosa adjacent to a neoplastic lesion but in the entire colon and rectum. A more recent study ${ }^{27}$ where an in vivo injection of $\mathrm{BrdU}$ was carried out in 75 patients with adenocarcinoma, showed no difference in proliferative activity between caecum, transverse colon, descending colon, sigmoid, and rectosigmoidal junction. Comparison of these colonic sites with the rectum showed a significantly lower PI\% in the rectal mucosa. The distribution of the label along the crypt was also significantly different. Therefore, it cannot be excluded that the inhibiting effect of calcium on cell proliferation may be different in the rectum from that in the colon.

A postulated mechanism by which calcium may exhibit its protective effect on colonic epithelium is by binding free fatty acids and secondary bile acids in the colonic lumen. ${ }^{28}$ Analysis of faecal lipids before and after six months of intervention in the same study group essentially showed evidence of increased precipitation of calcium salts of fatty acids but this did not lead to a decrease in the concentration of free fatty acids in this study (Weisgerber et al, submitted data). This finding is in agreement with no effect of calcium on cell proliferation.

Another postulated mechanism by which calcium may act on colonic epithelium is direct stimulation of cell differentiation. ${ }^{29}$ An insight into this can be obtained from the results on calcium excretion in faeces and urine. Renal calcium excretion in these patients was lower than obligatory renal calcium loss under conditions of calcium balance. Renal saving dominating obligatory renal loss is probably caused by a negative calcium balance at entry into the study despite reasonably high calcium intake; the reason for this being a comparatively low calcium absorption. During intervention, almost the entire amount of supplemented calcium was excreted via faeces, again implying a low calcium absorption capacity in this study group.

As shown by the positive correlation between the soluble calcium concentration in faeces and mucosal PI\%, it may be necessary for calcium to enter the colonocyte to exhibit its inhibiting effect on crypt cell proliferation. In patients with limited calcium absorption and low calcium uptake into the intestinal cell, high calcium supplementation would not decrease cell proliferation because passive transport through the colonic epithelium is paracellular. Decreasing calcium absorption with increasing age is a well recognised phenomenon and may be one reason why elderly persons exhibit a higher proliferative activity in the intestinal mucosa. Supplementation of $2 \mathrm{~g} /$ day calcium in young volunteers (mean age 27 years) does cause urinary calcium to increase significantly from $134 \mathrm{mg}$ to $172 \mathrm{mg}$ on average, indicating increased net calcium absorption. ${ }^{30}$ 
As calcium absorption in the colon is dependent on 1,25-dihydroxyvitamin $\mathrm{D},{ }^{31} 32$ calcium supplements alone may not be effective in patients with low calcium absorption. Calcium intervention in 79 adenoma patients (mean age 61 years) failed to reduce crypt cell production rate after 12 months compared with placebo. ${ }^{19}$ The only longterm trial that showed reduction of epithelial proliferation after six months of intervention with $1500 \mathrm{mg} /$ day was conducted in FAP patients (mean age 38 years), whose blood concentrations of vitamin $\mathrm{D}$ metabolites were above the normal range, indicating sufficient vitamin D supply. ${ }^{18}$ Nevertheless, several short-term studies in elderly high risk patients have shown a protective effect of calcium on cell proliferation in sigmoidal and rectal mucosa. ${ }^{12-14}$ It is possible that calcium exerts only a transient effect on intestinal proliferation and that in the long term limited calcium absorption hinders a protective effect. It may be useful for on going intervention studies ${ }^{33}$ to measure serum concentrations of vitamin D metabolites as a possible discriminating determinant between 'responders' and 'nonresponders' to calcium intervention.

This study was supported by the Program 'Europe against Cancer'. The authors are grateful to the following gastroenterologists who were involved in patient recruitment: $C$ Ginsbach (Klinikum der Stadt Ludwigshafen), H J Hilswicht (Städt Krankenhaus Weinheim), U Ohl (Städt Krankenhaus (Städt Krankenhaus Weinheim), U Ohl (Städt Krankenhaus
Pforzheim), W Rexroth (St Josefskrankenhaus Heidelberg), W Pforzheim), W Rexroth (St Josefskrankenhaus Heidelberg), W Scheppach (Medizinische Universitätsklinik Würzburg), R
Singer (Speyererhof Heidelberg), J C Weber (Medizinische Singer (Speyererhof Heidelberg), J C Weber (Medizinische
Klinik Bruchsal). We should also like to thank Sandoz AG, Nürnberg, for providing the medication and additional financia support to conduct faecal analysis.

1 Bleiberg H, Buyse M, Galand P. Cell kinetic indicators of premalignant stages of colorectal cancer. Cancer 1985; 56: 124-9.

2 Lipkin $M$, Enker WE, Winawer SJ. Tritiated-thymidine labeling of rectal epithelial cells in 'non-prep' biopsies of individuals at increased risk for colonic neoplasia. Cancer Lett 1987; 37: 153-61

3 Risio M, Lipkin M, Candelaresi G, Bertone A, Coverlizza S, Rossini FP. Correlations between rectal mucosa cell proliferation and the clinical and pathological features of nonfamilial neoplasia of the large intestine. Cancer Res 1991; 51: 1917-21.

4 Deschner EE, Maskens AP. Significance of the labeling index and labeling distribution as kinetic parameters in index and labeling distribution as kinetic parameters in colorectal mucosa of cancer patien

5 Scalmati A, Roncucci L, Ghidini G, Biasco G, Ponz de Leon $M$. Epithelial cell kinetics in the remaining colorectal mucosa after surgery for cancer of the large bowel. Cancer Res 1990; 50: 7937-41.

6 Franklin WA, McDonald GB, Stein HO, Gatter KC, Jewell DP, Clarke LC, et al. Immunohistologic demonstration of abnormal colonic crypt cell kinetics in ulcerative colitis. Hum Pathol 1985; 16: 1129-32.

7 Biasco G, Paganelli GM, Miglioli M, Brillanti S, Di Febo G, Gizzi G, et al. Rectal cell proliferation and colon cancer risk in ulcerative colitis. Cancer Res 1990; 50: 1156-9.

8 Lipkin M, Blattner WA, Gardner EJ, Burt RW, Lynch H, Deschner E, et al. Classification and risk assessment of individuals with familial polyposis, Gardner's syndrome, and familial non-polyposis colon cancer from thymidin labeling patterns in colonic epithelial cells. Cancer Res 1984; 44: 4201-7.

9 Rozen P, Fireman Z, Fine N, Chetrit A, Lubin F. Recta epithelial proliferation characteristics of first degree relatives of sporadic colon cancer patients. Cancer Lett 1990; 51: 127-32.

10 Lipkin M, Newmark $H$. Effect of added dietary calcium on colonic epithelial-cell proliferation in subjects at high risk for familial colonic cancer. $N$ Engl f Med 1985; 313: 1381-4.

11 Rozen P, Fireman Z, Fine N, Wax Y, Ron E. Oral calcium suppresses increased rectal epithelial proliferation of persons at risk of colorectal cancer. Gut 1989; 30: 650-5.

12 Barsoum GH, Hendrickse C, Winslet MC, Youngs D, Donovan IA, Neoptolemos JP, et al. Reduction of mucosal crypt cell proliferation in patients with colorectal mucosal crypt cell proliferation in patients with colorectal Brf Surg 1992; 79: 581-3.

13 Wargovich MJ, Isbell G, Shabot M, Winn R, Lanza F, Hochman L, et al. Calcium supplementation decrease rectal epithelial cell proliferation in subjects with sporadic adenoma. Gastroenterology 1992; 103: 92-7.

14 O'Sullivan KR, Mathias PM, Beattie S, O'Morain C. Effect of oral calcium on colonic crypt cell proliferation in patients with adenomatous polyps of the large bowel. European fournal of Gastroenterology and Hepatology 1993; 5: 85-9.

15 Gregoire RC, Stern HS, Yeung KS, Stadler J, Langley S, Furrer $\mathrm{R}$, et al. Effect of calcium supplementation on Furrer $\mathrm{R}$, et al. Effect of calcium supplementation on cancer. Gut 1989; 30: 376-82.

16 Bostick RM, Potter JD, Fosdick L, Grambsch P, Lamp $\mathrm{JW}$, Wood JR, et al. Calcium and colorectal epithelial cel proliferation: a preliminary randomized, double-blinded, placebo-controlled clinical trial. $\mathcal{F}$ Natl Cancer Inst 1993; 85: $132-41$.

17 Stern HS, Gregoire RC, Kashtan H, Stadler J, Bruce RW. Long-term effects of dietary calcium on risk markers for colon cancer in patients with familial polyposis. Surgery 1990; 108: 528-33.

18 Thomas MG, Thomson JPS, Williamson RCN. Oral calcium inhibits rectal epithelial proliferation in familial adenomatous polyposis. Br 7 Surgery 1993; 80: 499-501.

19 Armitage NC, Rooney PS, Gifford K-A, Clarke PA Hardcastle JD. The effect of calcium supplements on rectal mucosal proliferation. $B r \mp$ Cancer $1995 ; 71: 186-90$.

20 Weisgerber UM, Boeing H, Nemitz R, Raedsch R, Waldherr R. Proliferating cell nuclear antigen (clone 19A2) correlates with 5-bromo-2-deoxyurdine labelling in human colonic epithelium. Gut 1993; 34: 1587-92.

21 Armitage P, Berry G. Statistical methods in medical research. Oxford, Blackwell Scientific, 1987: 182

22 Nordin BEC, Marshall DH. Dietary requirements for calcium. In: Nordin BEC, ed. Calcium in human biology. London: Springer, 1988: 447-71.

23 Kramer MS, Shapiro SH. Scientific challenges in the application of randomized trials. F Am Med Ass 1984; 252: 2739-45.

24 McDonald CJ, Mazzuca SA, McCabe GPJ. How much of the placebo effect is really statistical regression? Stat Med 1983; 2: 417-27.

25 Terpstra OT, van Blankenstein $M$, Dees J, Eilers GA Abnormal pattern of cell proliferation in the entire colonic mucosa of patients with colon adenoma or cancer. Gastroenterology 1987; 92: 704-8.

26 Ponz de Leon M, Roncucci L, Di Donato P, Tassi I Smerieri O, Amorico MG, et al. Pattern of epithelial cell proliferation in colorectal mucosa of normal subjects of patients with adenomatous polyps or cancer of the large bowel. Cancer Res 1988; 48: 4121-6.

27 Potten CS, Kellett M, Roberts SA, Rew DA, Wilson GD. Measurement of in vivo proliferation in human coloMeasurement of in vivo proliferation in human colorectal

28 Newmark HL, Wargovich MJ, Bruce WR. Colon cancer and dietary fat, phosphate, and calcium: a hypothesis. $\mathcal{J}$ Natl Cancer Inst 1984; 72: 1323-5.

29 Whitfield JF. Calcium signals and cancer. Crit Rev Onco 1992; 3: 55-90.

30 Van der Meer R, Welberg JWM, Kuipers F, Kleibeuker JH, Mulder NH, Termont DSL, et al. Effects of supplementary calcium on the intestinal association of calcium, phosphate and bile acids. Gastroenterology 1990; 99: 1653-9.

31 Petith MM, Wilson HD, Schedl HP. Vitamin D dependence of in vitro calcium transport and mucosal calcium binding protein in rat large intestine. Gastroenterology binding protein in

32 Favus MJ, Kathpalia SC, Coe FL, Mond AE. Effects of diet calcium and 1,25-dihydroxyvitamin D3 on colon calcium calcium and 1,25-dihydroxyvitamin D3 on colon

33 Faivre J, Doyon F, Boutron MC. The ECP calcium fibre polyp prevention study. The ECP Colon Group. Eur $\mathcal{F}$ Cancer Prev 1991; 1 (suppl 2): 83-9. 